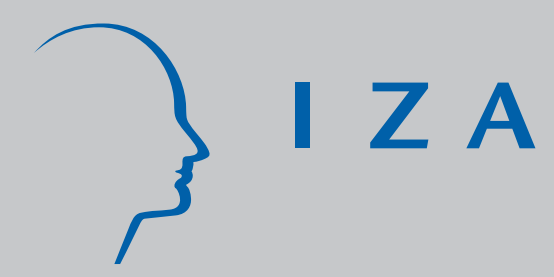

IZA DP No. 3441

From Illegal to Legal:

Estimating Previous Illegal Experience among New Legal Immigrants to the United States

Guillermina J asso

Douglas S. Massey

Mark R. Rosenzweig

J ames P. Smith

April 2008 


\title{
From Illegal to Legal: Estimating Previous Illegal Experience among New Legal Immigrants to the United States
}

\author{
Guillermina Jasso \\ New York University and IZA \\ Douglas S. Massey \\ Princeton University
}

Mark R. Rosenzweig

Yale University

James P. Smith

Rand Corporation and IZA

Discussion Paper No. 3441

April 2008

IZA

P.O. Box 7240

53072 Bonn

Germany

Phone: +49-228-3894-0

Fax: +49-228-3894-180

E-mail: iza@iza.org

Any opinions expressed here are those of the author(s) and not those of IZA. Research published in this series may include views on policy, but the institute itself takes no institutional policy positions.

The Institute for the Study of Labor (IZA) in Bonn is a local and virtual international research center and a place of communication between science, politics and business. IZA is an independent nonprofit organization supported by Deutsche Post World Net. The center is associated with the University of Bonn and offers a stimulating research environment through its international network, workshops and conferences, data service, project support, research visits and doctoral program. IZA engages in (i) original and internationally competitive research in all fields of labor economics, (ii) development of policy concepts, and (iii) dissemination of research results and concepts to the interested public.

IZA Discussion Papers often represent preliminary work and are circulated to encourage discussion. Citation of such a paper should account for its provisional character. A revised version may be available directly from the author. 


\section{ABSTRACT}

\section{From Illegal to Legal: Estimating Previous Illegal Experience among New Legal Immigrants to the United States*}

This paper develops a framework for estimating previous illegal experience among annual cohorts of new legal immigrants to the United States - using public-use administrative microdata alone, survey data alone, and the two jointly - and provides estimates for the FY 1996 cohort of new immigrants, based on both administrative and survey data. Our procedures enable assessment of type of illegal experience, including entry without inspection, visa overstay, and unauthorized employment. We compare our estimates of previous illegal experience to estimates that would be obtained using administrative data alone; examine the extent of previous illegal experience by country of birth, immigrant class of admission, religion, and geographic residence in the United States; and estimate multivariate models of the probability of having previous illegal experience. To further assess origins and destinations, we carry out two kinds of contrasts, comparing formerly illegal new legal immigrants both to fellow immigrants who do not have previous illegal experience and also to the broader unauthorized population, the latter using estimates developed by DHS (2002), Passel (2002), and Costanzo et al. (2002).

JEL Classification: F22, C42, K42

Keywords: illegal immigration, legal immigration, administrative data, survey data

Corresponding author:

Guillermina Jasso

Department of Sociology

New York University

295 Lafayette Street, $4^{\text {th }}$ Floor

New York, NY 10012-9605

USA

E-mail: gj1@nyu.edu

\footnotetext{
* Authors are listed in alphabetical order. The New Immigrant Survey Pilot research was supported by the National Institutes of Health (NICHD and NIA) under grant HD33843, with partial support from the U.S. Immigration and Naturalization Service and the National Science Foundation. Early versions of portions of this paper were presented at the Conference on "The Effects of Immigrant Legalization Programs on the United States: Scientific Evidence on Immigrant Adaptation and Impacts on the U.S. Economy and Society," sponsored by NICHD, the U.S. Immigration and Naturalization Service, and the U.S. Census Bureau, September 2002, and at the annual meeting of the American Sociological Association, Atlanta, Georgia, August 2003. We are grateful to participants at those meetings and other colleagues for many valuable comments and suggestions, especially Rebecca Clark, Linda Gordon, Michael Hoefer, Carolyn Jones, Jennifer Martin, Lisa S. Roney, Marian L. Smith, and Robert Warren; and we thank the anonymous reviewers and editors for their close reading and valuable comments. We also gratefully acknowledge the intellectual and financial support of New York University, University of Pennsylvania, Princeton University, the RAND Corporation, and Yale University. This paper is forthcoming in International Migration Review.
} 


\section{INTRODUCTION}

Every year several hundred thousand persons become illegal aliens in the United States either because they enter illegally or because, having entered legally, they lapse into illegality by overstaying a visitor visa or engaging in unauthorized employment - adding what official estimates put at an average annual net increase of 350,000 during the 1990s (DHS 2002 Yearbook:213) and 515,000 in the period 2000-2006 (Hoefer, Rytina, and Campbell 2007:3). ${ }^{1}$ And every year some three-quarter million to a million persons become lawful permanent residents (LPRs) of the United States ${ }^{2}$ - averaging 781,848 in the 1991-1995 period and 771,307 in the 1996-2000 period, then increasing to an average of 980,344 in the 2000-2005 period and a total of $1,266,047$ in $2006 .{ }^{3,4}$ These include persons formerly illegal who are not only acquiring or regaining legal status but are in fact acquiring the most coveted of all legal statuses, that of a legal immigrant, admitted for lawful permanent residence and starting the clock on their way to naturalization. Despite the obvious importance of this previously-illegal subset of new immigrants acquiring LPR under routine, non-IRCA-legalization provisions of U.S. law, little is

1 In March 2003, the U.S. Immigration and Naturalization Service (INS) ceased to exist. The agency's statistical activities, housed in the Statistics Division, were transferred to the new Office of Immigration Statistics (OIS) in the Management Division of the Department of Homeland Security (DHS). These estimates of the illegal population were developed first at INS and subsequently at DHS. The estimates in the DHS 2002 Yearbook are a summary of a comprehensive report prepared by Warren (2003).

2 The acronym LPR will be used for both lawful permanent resident and lawful permanent residence. The context should make clear whether reference is to a person or to a status.

3 Immigration figures refer to the total, non-IRCA-legalization number of new LPRs. This number was reported as "total non-legalization" in Table 4 of the INS and DHS Yearbooks through the 2004 Yearbook. The Yearbooks for 2005 and 2006 do not report the non-IRCAlegalization total, but it is possible to obtain it by subtracting the IRCA legalization total from the grand total in Table 7. During the period 1991-2006 IRCA legalizations declined from a high of over a million in 1991 to less than a thousand in every year since 1998, with a low of 8 in 1999 and totals of 188 and 217 in Fiscal Years 2005 and 2006, respectively (DHS Yearbooks, Table 4 through 2004, Table 7 thereafter).

4 In contrast to the estimates of net annual increases to the illegal population, the number of new LPRs does not represent a net addition to the population of LPRs (and LPRs who have naturalized), as immigrants admitted in earlier years may have emigrated or died (or had their permanent residence revoked). 
known about its size and characteristics.

This paper develops a framework and procedures for estimating previous illegal experience among immigrants newly admitted for lawful permanent residence, based on both administrative records and survey data, and implements the procedures on a probability sample of the FY 1996 immigrant cohort, for which both administrative and survey data are available as part of the New Immigrant Survey (NIS) project. As will be seen, partial estimates can be obtained from either administrative records or survey data alone. Thus, it will be possible to construct a comprehensive portrait of previous illegal experience among new legal immigrants across many cohorts, assessing differences over time and comparing partial estimates with each other and with fuller estimates making use of both administrative and survey data based on the NIS cohorts (1996, 2003, and future cohorts). ${ }^{5}$

Information on the size and characteristics of the subset of new lawful permanent residents with previous illegal experience is important for several reasons. First, it provides a glimpse into behavioral dimensions of the immigration experience. Second, this information constitutes a kind of barometer of tolerance for illegal immigration - if marrying or hiring illegals is widespread. Third, it alerts to and signals critical elements of the process of incorporation into the U.S. society and economy; like survivors of World War II who spent the war years with false identities, new immigrants who have been illegal have additional things to learn and unlearn, beyond those in common with other new LPRs. Fourth, and relatedly, information on illegal experience is important for estimating the returns to experience in the United States, which may differ according to type of experience, including whether the experience was legal or illegal. Fifth, more broadly, immigrants with previous illegal experience may differ systematically from immigrants with no previous illegal experience on a large range

5 There are many a priori reasons to expect variation across cohort (Jasso 2004) conditions in origin countries change, U.S. immigration laws and policies change, and sometimes there are pivotal events, such as the terrorist attacks on the United States in 2001. 
of characteristics and behavior, including health, English skill, and remittances. ${ }^{6}$ Sixth, information on previous illegal experience among non-IRCA-legalization immigrants will enable comparison with IRCA-legalized immigrants, making it possible to assess the effects of different routes to legalization. ${ }^{7}$ Finally, estimates of formerly illegal new LPRs are a component in some approaches for estimating the size of the illegal population (e.g., in the approach used to obtain the estimates reported in the DHS 2002 Yearbook and more fully described in Warren 2003).

The framework developed in this paper incorporates three main ingredients. First, it distinguishes across types of illegality - entry without inspection, visa overstay, and unauthorized employment. Second, it distinguishes across channels of legalization - for example, whether LPR is acquired in one of the admission classes for illegals (such as the registry provisions) or instead in a general admission class (such as family, employment, or lottery). Third, it distinguishes between three types of information - based on administrative records alone, based on survey data alone, and based jointly on both.

Procedures developed in this paper to estimate the previous illegal experience of new legal immigrants build on three research traditions, one which surveys new legal immigrants, exemplified by North's (1978) study of the FY 1970 cohort of immigrants and Portes' study of the FY 1974 cohort (Hirschman 1978; Portes 1979; Portes and Bach 1980), a second which obtains and analyzes information from migrants about their legal status, exemplified by the Mexican Migration Project directed by Massey (see, for example, Massey 1987, Singer and Massey 1998, and Durand and Massey 2004), and a third which uses administrative data to discern immigrant characteristics, exemplified by Jasso and Rosenzweig (1982) and Jasso,

6 Early information from the baseline round of the Pilot for the New Immigrant Survey (Jasso, Massey, Rosenzweig, and Smith 2000b:135-137) indicates, for example, that new legal immigrants with experience as an entry without inspection differ from other immigrants in schooling, earnings, earnings gain, and travel outside the United States before acquiring LPR.

7 IRCA-legalized immigrants appear to have had many positive outcomes. As discussed by Powers and Seltzer (1998) and Powers, Kraly, and Seltzer (2004), the IRCA-legalized have experienced upward occupational mobility, relative to both jobs in the origin country and jobs while illegal in the United States. 
Rosenzweig, and Smith (2000).

This paper also contributes to the wider literature on characteristics of the illegal population and of illegals who legalize (Bean, Edmonston, and Passel 1990; Costanzo et al. 2002; Espenshade 1995; Passel, Van Hook, and Bean 2006; Powers, Kraly, and Seltzer 2004; Powers and Seltzer 1998). As the United States contemplates a range of immigration policy options, including a variety of new legalization programs, it is useful to assemble the information currently available about illegal aliens potentially eligible for legalization and about legal immigrants with previous illegal experience. Such information will enable assessment of their characteristics, of the likelihood of their successful adaptation to the United States, and of their impacts on the United States and its people. Note that whatever the outcome of policy discussions, such information makes possible a more cogent policy that includes targeted provisions to augment the benefits of the policy and mitigate its costs.

The paper is organized as follows: In Section 2 we present the framework for estimating previous illegal experience among new legal immigrants; we describe procedures for estimating the three types of illegal experience, along with several indicators, using both official U.S. immigration data and survey data, in particular, data from the New Immigrant Survey Pilot (NIS-P). Section 3 reports estimates of previous illegal experience among the FY 1996 immigrant cohort surveyed as part of the NIS-P, and compares them to estimates that would be obtained using administrative data alone. Section 4 examines previous illegal experience by gender, schooling, country of birth, class of admission, religion, and state of residence, and presents estimates of multivariate models of the probability of having previous illegal experience. In Section 5 we look more closely at the origins and destinations of new immigrants with previous illegal experience, comparing them to the origins and destinations of both their cohortmates who do not have previous illegal experience and to the broader unauthorized population, the latter using estimates developed by DHS (2002), Passel (2002), and Costanzo et al. (2002). A short note concludes the paper. 


\section{FRAMEWORK FOR ESTIMATING THE PREVIOUS ILLEGAL EXPERIENCE OF NEW LEGAL IMMIGRANTS}

We begin by considering the three main types of illegality. Next we consider the three main channels of legalization. Then we turn to the two main data sources, administrative data and survey data. Finally, we present measures of particular types of illegal experience - EWI, visa overstay, unauthorized employment - based on administrative data, NIS-P data, and both administrative data and NIS-P data jointly.

\subsection{Types of Illegality}

There are three main types of previous illegal experience - entry without inspection (EWI), visa overstay, and unauthorized employment. ${ }^{8}$ It is possible for a person to have experience with only one, with two, or with all three types of illegality. For example, an EWI person may never have engaged in unauthorized employment, and as well may never have overstayed a visa. Similarly, a person may have engaged in unauthorized employment without ever being EWI or overstaying a visa. On the other hand, a person may have all three kinds of experience.

Our goal is to construct three binary variables, one for each type of illegality, and to code each new legal immigrant according to whether he or she has ever been illegal in each of the three ways. Accordingly, it will be possible to estimate the proportion of a cohort that has ever been EWI, the proportion that has ever overstayed a visa, and the proportion that has ever worked without authorization. Of course, the total proportion with previous illegal experience is likely to be smaller than the sum of the proportions with each type of illegal experience.

\subsection{Channels of Legalization}

There are three main ways that an illegal migrant becomes a legal permanent resident. ${ }^{9}$

8 We do not consider other types of illegality - such as illegality due to being inadmissible. Under the Immigration and Nationality Act, there are currently ten classes of grounds of inadmissibility; these cover such matters as health, crime, and security.

9 We do not consider the less common channels of legalization, such as being the beneficiary of a private bill in Congress. 
First, the illegal may acquire lawful permanent residence through provisions of U.S. immigration law that are unrelated to previous illegal experience; for example, an illegal may be sponsored by an employer or by an adult child or by a U.S. citizen spouse. Second, the illegal may acquire LPR through provisions of U.S. immigration law that are specifically designated for illegals; for example, an illegal may become legal through the registry provisions or via cancellation of removal. $^{10}$ Third, a special legalization program may be instituted for a subset of illegal aliens (and sometimes, subsequently, for their spouses and minor children). For example, the most recent broadbased legalization program, established by the Immigration Reform and Control Act of 1986 (IRCA), enabled almost three million persons to legalize under two main subprograms, one for individuals who had resided continuously in the United States since January 1, 1982 and the other for individuals who had been employed in agriculture during a specified time period. More recently, the Nicaraguan Adjustment and Central American Relief Act (NACARA) of 1997 permitted illegals from Central America and the former Soviet Union to become legal permanent residents (DHS, 2003 Yearbook, p. 189).

\subsection{Data Sources on Previous Illegal Experience of New Legal Immigrants}

We begin with information available in the public-use administrative microdata on annual cohorts of legal immigrants compiled by the Statistics Division of the U.S. Immigration and Naturalization Service and its successor, the Office of Immigration Statistics in the Department of Homeland Security. Next we briefly describe the NIS and the pertinent information it provides.

\subsubsection{Information on Previous Illegal Experience in Administrative Data}

A new legal permanent resident's previous illegal experience may or may not be known to the U.S. government. The U.S. government has direct knowledge only about those persons

10

Registry provisions provide for the adjustment to LPR of persons who have resided continuously in the United States since a given date; currently, that date is set at January 1, 1972. Cancellation of removal, together with the kindred suspension of deportation provisions in effect before 1997, similarly provide for adjustment to LPR. On these and other provisions of immigration law, further information may be found at the State Department and USCIS websites (http://www.unitedstatesvisas.gov and http://www.uscis.gov). 
who have been apprehended or made their status known during the LPR application process or an amnesty process. Moreover, even when a government official has information about a new LPR's previous illegal experience, the information is not necessarily recorded or, if recorded, not necessarily incorporated in the electronic immigrant records which form the basis for published tabulations in the Yearbooks, for public-use administrative microdata on immigrants, and for the sampling design in surveys such as the New Immigrant Survey. 11,12

The information in the electronic immigrant records includes several pertinent characteristics, as follows:

Immigrant Class of Admission. The immigrant class of admission - or "immigrant visa" - indicates the channel of legalization - that is, the section of law under which a person qualifies for admission to LPR. For example, as noted in section 2.2, a person may qualify under a regular visa category (such as spouse of a U.S. citizen or world-class researcher or refugee) or under a special category for legalizing illegals. 13

The set of admission classes which indicate previous illegal experience are of three main kinds - registry provisions, suspension-of-deportation/cancellation-of-removal, and special legalization programs - and their codes can be used to construct measures of previous illegal experience. The codes for legalization via the registry provisions are Z33, Z03, and Z66. The codes for legalization via suspension-of-deportation/cancellation-of-removal are Z11, Z13, Z14, Z15, Z56, and Z57. Special legalization programs are in effect in different years, and each has its own visa codes. For example, the special legalization program established by NACARA, which provides relief from deportation for subsets of illegal aliens, is associated with a special visa code

11 The annual statistical reports were titled Annual Report of the Immigration and Naturalization Service until 1977, Statistical Yearbook of the Immigration and Naturalization Service in the years 1978-2001, and Yearbook of Immigration Statistics since 2002.

12 Public-use administrative microdata on the annual immigrant cohorts for the Fiscal Years 1972-2000 are available for sale by the National Technical Information Service.

13 Brief overviews of U.S. laws governing immigrant visa allocation may be found in the INS and DHS Yearbooks, in the USCIS and State Department websites, and in numerous books and articles (e.g., Jasso, Rosenzweig, and Smith 2000; Smith and Edmonston 1997). 
(NC6) which can be used to identify previous illegal experience.

Note that the previous illegality of illegals who legalize via one of the regular visa categories (e.g., sibling of U.S. citizen) cannot be identified from the class of admission. However, as will be seen below, if such an immigrant entered without inspection and is permitted to adjust status, then the entry without inspection is recorded in the field for nonimmigrant class of admission.

Note also that although the registry, suspension-of-deportation/cancellation-of-removal, and special-legalization program codes unambiguously identify the immigrant as having previous illegal experience, they do not necessarily reveal the type of illegal experience (i.e., EWI, overstay, or unauthorized employment). ${ }^{14}$

Nonimmigrant Class of Admission. For those immigrants who adjust to LPR in the United States, the electronic immigrant record provides the nonimmigrant class of admission. For example, the new immigrant may have spent several years as a student or working in one of the many nonimmigrant temporary worker categories, or may have spent a few months with a tourist visa.

New immigrants who adjust from the EWI type of illegality are given a special code in the adjustee nonimmigrant visa field (EWI or WI). This code can be used to construct a measure of previous EWI illegality.

Additionally, some adjustees receive a UU code, which indicates "unknown" and is sometimes thought to be a euphemism for illegal status, indeed for EWI experience. Researchers working with particular cohorts or sets of data can decide whether to use the UU code to infer illegality, or to distinguish between subsets of persons whose illegality is inferred in other ways.

14 Moreover, IRCA instituted stringent confidentiality provisions, so that immigrant records pertaining to IRCA-legalized persons are not part of public-use administrative microdata or of the sampling frame for the New Immigrant Survey cohort samples. For example, the FY 1996 public-use administrative microdata exclude the records for 4,635 IRCA-legalized persons; these include not only the pre-1982 and agricultural subsets but also the extended voluntary departure subset. In contrast, persons who legalized under the Cuban-Haitian entrant provisions of IRCA (1996 Yearbook, p. A3-3) are included in the public-use administrative microdata (and listed under "other adjustments" in the 1996 Yearbook, Table 7, p. 41). 
Other information. The immigrant record includes further information which can be used to infer previous illegal experience. This additional information includes a code for whether the immigrant is a new arrival or an adjustee and the date (month and year) of admission to legal permanent residence. $^{15}$ For adjustees, the immigrant record also includes the year of last entry with the nonimmigrant visa. ${ }^{16}$

\subsubsection{Information on Previous Illegal Experience in Survey Data}

\section{and in NIS-P Data}

Survey Data. As has been amply documented by Massey and his associates (e.g., Massey 1987, Singer and Massey 1998, and Durand and Massey 2004), survey data can obtain both direct measures of previous illegality and also additional information from which illegality can be inferred. Examples of direct questions are questions which ask whether the respondent has ever been apprehended or ever overstayed a visa. Examples of questions from which illegality can be inferred include parallel trip histories and employment histories. If, say, a respondent reports entry with a tourist visa and starting a new job in the United States at the same time, then it is safe to infer unauthorized employment. Moreover, survey information can be used in combination with administrative information to infer illegality; for example, as already noted, if inception of U.S. residence, ascertained from survey data, precedes the date of admission to LPR of a new-arrival immigrant and the immigrant visa is not one of the employment preferences which offer choice of consular processing, then the immigrant was living illegally in the United States.

15 Some immigrants classified by INS/CIS as "new arrival" immigrants are already residing in the United States when they obtain LPR; they may be eligible for an immigrant visa but ineligible to adjust to LPR in the United States (for example, because they are not currently in a legal status) or they may be employment-based immigrants who choose consular processing. Such individuals go to a U.S. consular office abroad to obtain their immigrant documents and then are admitted to LPR at a port of entry. Survey data, such as NIS data, can identify whether residence and/or employment in the United States precedes the date of admission to LPR of a new-arrival immigrant.

16 Warren (unpubl, pp. 6-7) uses this information to infer previous illegal experience, reasoning that in most cases nonimmigrant visas would not be valid for periods longer than six years. 
NIS-P Data. The New Immigrant Survey is a new plan for nationally representative, longitudinal studies of immigrants and their children that will provide new kinds of data that will help answer many of the important questions about immigration; the data are and will be publicly available to researchers. ${ }^{17}$ The sampling frame for the cohorts surveyed in the NIS is the administrative list of new LPRs for a particular time period, and the information in the immigrant record is used for the sampling design (for example, to over- or undersample by class of admission) and becomes part of the data set.

Because such a design had not previously been attempted, the New Immigrant Survey Pilot carried out a survey of a probability sample of legal immigrants in the FY 1996 cohort. The sampling frame consisted of all persons admitted to permanent residence in July and August of $1996(N=148,987)$. The sample design oversampled employment-based immigrants, a relatively small set in whom there is considerable interest, and undersampled child immigrants, who are numerous. The sample numbered 1,984 persons, of whom 1,839 were adult immigrants.

The overall response rate was $62 \%$, yielding an interviewed sample of 1,224 persons, of whom 1,127 are adult immigrants. ${ }^{18}$ One of the goals of the NIS-P was to test methods for locating immigrants for their cost-effectiveness; calculations indicate that had the best methods been used on all sampled immigrants, the response rate would have been at least $75 \%$. On the basis of checks on seasonality and contrasts between interviewed and noninterviewed sampled immigrants, no evident biases in the sample could be detected. Thus, the final NIS-P sample appears to be a representative sample of new immigrants admitted in FY 1996. For further information on NIS-P design and data quality, see Jasso, Massey, Rosenzweig, and Smith

17 Brief overviews of the New Immigrant Survey project may be found in Jasso (2008) and Jasso, Massey, Rosenzweig, and Smith (2003); for comprehensive overview, see Jasso, Massey, Rosenzweig, and Smith (in press).

18 As discussed in Jasso, Massey, Rosenzweig, and Smith (2000b), the number of interviewed adult immigrants was 1,130; however, three of the interviewed adults lived in Puerto Rico, Guam, and the Virgin Islands, and because the sampling properties of these cases differ from the rest of the sample, they are excluded from the analysis. 
$(2000 \mathrm{ab}){ }^{19}$

The NIS-P sample was interviewed at a baseline round, with follow-up interviews six months and twelve months after the baseline interview. To test systems for maintaining contact and reducing attrition, a randomly selected half of the sample was also interviewed three months after the baseline round.

The NIS design stipulates that immigrants be interviewed in their preferred language. Accordingly, the NIS-P questionnaires were translated into six languages (Spanish, Chinese, Russian, Polish, Korean, and Vietnamese). Trained bilingual interviewers conducted interviews in these and 11 additional languages.

Entry Without Inspection. The baseline round of the NIS-P obtained information on the first and last trips each respondent had made to the United States, including information on whether the respondent had entry documents and, if so, what kind of entry documents. The section of the questionnaire began with the preface, "People come to the United States for many different reasons, with different kinds of documents, and sometimes without documents." The two questions on entry documents asked, "For that first visit, did you have a visa or other entry document?" and "Did you have a visa or other entry document at the time you entered the US

19

We carried out two sets of contrasts: (1) between immigrants admitted in July and August (the basis for the NIS-P sample) and immigrants admitted in the other ten months of FY 1996, using public-use administrative microdata for the cohort; and (2) between immigrants drawn into the NIS-P sample and immigrants who completed interviews (this last contrast reported in Jasso, Massey, Rosenzweig, and Smith 2000b:130). Both contrasts focused on immigrants aged 18 and older. There are no appreciable differences in most characteristics; for example, the percent male is $43.8 \%$ in the July-August adult immigrant population and $44.4 \%$ in the other ten months, and it is the same $(44.7 \%)$ in both the full sample and the interviewed. The largest differences are as follows: The percent born in Mexico is higher by two percentage points in the July-August subcohort (16.9\% versus $14.9 \%$ ) but about the same among the interviewed and noninterviewed sampled immigrants $(15.0 \%$ and $15.1 \%)$. The percent entering as spouse of U.S. citizen is greater by three percentage points in the July-August subcohort $(27.9 \%$ versus $24.6 \%)$; it is higher by one percentage point among the interviewed $(28.8 \%$ versus $27.7 \%)$. The proportion with the WI nonimmigrant code is greater by two percentage points in the JulyAugust subcohort (14.3\% versus 12.3\%); however, it is one percentage point less among the interviewed than in the full sample $(12.3 \%$ versus $13.3 \%)$. Thus, there are no appreciable differences in most characteristics in the two contrasts. [Note that the proportions among the larger set of immigrants of all ages or among different subsets may differ from the proportions just discussed. For example, the percent born in Mexico among new LPRs is larger among children than among adults.] 
this last time?" Individuals who report having no entry documents of any kind are presumed to have entered without inspection. ${ }^{20}$

Visa Overstay. The 12-month round included the question, "During any of the times you were in the United States before becoming a permanent resident, did you ever stay longer than you were authorized under the terms of your visa or other entry document?" This question provides a direct measure of visa overstay experience.

Apprehension by INS. The 12-month round also included the question, "During any of the times you were in the United States before becoming a permanent resident, were you ever apprehended in the United States by the INS (Immigration and Naturalization Service)?" This question provides information on general illegal experience.

Additional Information. The NIS-P also obtained information which, combined with the administrative information, can be used to infer illegal experience. Such information includes the date of the first trip, the date of the last trip, and the date on which the current U.S. job was started (month and year obtained for all dates).

\subsection{Measures of Types of Illegal Experience}

Our review of types of illegal experience and of data sources indicates that (1) some measures of illegal experience do not reveal the type of illegality, so that it is necessary to construct a new fourth category of unspecified illegal experience, and (2) there are multiple measures for each of the three types of illegal experience as well as for the new fourth category. Accordingly, we constructed binary measures for several indicators of each of the four groupings, separately by data source. The measures are not mutually exclusive. As already noted and as will be seen, an individual may have experience as, say, both an EWI and a visa overstay. As well, a given individual may satisfy the criteria for several of the indicators for one type of illegal experience. We also constructed a basic global measure for each of the four groupings - the

20 For the majority of NIS-P respondents, the "last trip" prior to interview was taken after admission to permanent residence (there being, presumably, pent-up demand for a trip abroad); thus, this question yielded few EWI cases. 
three types of illegal experience plus the unspecified illegal experience. Note that some of the administrative-data measures are available only for some legalization programs (and hence only for some years).

\subsubsection{Entry Without Inspection}

As the foregoing discussion indicates, there are three indicators of EWI experience in the administrative immigrant record and two in the NIS-P data. The three administrative-data indicators are: (1) the administrative record includes the nonimmigrant code EWI or WI; (2) the administrative record includes the nonimmigrant code UU; and (3) the administrative data includes the immigrant code for a special legalization program for EWI persons. The two NIS-P indicators are: (1) NIS-P data indicate that the immigrant entered without documents on the first trip to the United States; and (2) NIS-P data indicate that the immigrant entered without documents on the last trip to the United States.

Table 1 reports all the measures of previous illegal experience, separately by data source and by type of illegal experience. The EWI measures are in panel A.

\section{- Table 1 about here -}

Because of uncertainty surrounding the UU nonimmigrant code, we exclude it from our basic global measure of EWI experience. Moreover, in our analysis of the FY 1996 cohort, we exclude the third administrative-data indicator, because in that year the public-use administrative microdata do not include any cases of a special legalization program for persons who entered without inspection. Thus, the basic global measure of EWI experience used in this paper includes only the WI measure from the administrative record and the two NIS-P measures.

It is useful to consider whether our global EWI measure may be upwardly or downwardly biased. Given that the NIS-P did not collect information on entry without documents on any of the intermediate trips made by respondents, information based on this measure would understate the true extent of EWI experience - unless respondents who were EWI on an intermediate trip were also EWI on either the first or the last trip, in which case our measure is exactly correct and does not understate EWI experience. Among the adjustee immigrants with the WI nonimmigrant 
code, $83.3 \%$ reported entry without documents on the first trip, with 13.9 percent reporting documented entry and $2.8 \%$ non-responses. The $14 \%$ could represent individuals who, though entering with documents on the first trip, entered without documents the last time before admission to LPR; alternatively, they could be misreporting an undocumented first entry. If newarrival immigrants who have been in the United States previously and adjustee immigrants have similar migration histories and response styles, then our measure understates the EWI experience of new-arrival immigrants, given the absence of an independent measure such as the WI code in INS data. However, the potential for unmeasured EWI experience among new-arrival immigrants is limited; the proportion of new-arrival immigrants who had made three or more trips to the United States, whose first trip was not as an LPR, and who did not report EWI experience on either the first or last trip - and are thus at risk of unmeasured EWI experience is 13 percent. $^{21}$

\subsubsection{Visa Overstay}

As shown in panel B of Table 1, the measures of overstay experience include two measures based on administrative data (a direct measure corresponding to some special legalization programs and the indirect measure used by Warren unpubl), one direct measure from the NIS-P, and two measures based jointly on NIS-P and administrative data

The direct administrative measure is available only for some legalization programs; for example, the code W26 designates overstays legalizing under IRCA. The direct NIS-P measure taps respondents who reported overstay experience.

We constructed a version of the indirect measure based on Warren's (unpubl) reasoning that adjustees whose last nonimmigrant entry was more than six years earlier are probably overstays. Our measure infers overstay experience if two criteria are satisfied: (1) adjustment is from a "visitor for pleasure" (B2) visa or its counterpart visa waiver code (WT), and (2) the last entry was before 1990 .

21 Within this $13 \%$ of new arrivals at risk of unmeasured EWI experience, a little under a quarter $(23 \%)$ register other kinds of illegal experience. 
The two joint measures represent inferences of visa overstay experience based on a combination of administrative and NIS-P data. Both involve immigrants who are new arrivals (in the technical sense, described in section 2.3.1, of being admitted to LPR at a U.S. port of entry upon arrival with an immigrant visa obtained from a consular office abroad). The first pertains to immigrants who report having made only one trip, with documents, to the United States (not counting entries subsequent to travel out of the United States for less than two weeks), and the date of that trip precedes the date of admission to LPR. The second pertains to immigrants whose last trip (again, not counting entries subsequent to travel out of the United States for less than two weeks) was with valid documents and precedes the date of admission to LPR. Behaviorally, these cases are consistent with a scenario in which the respondent was in the United States but ineligible to adjust status and thus left for a brief period to pick up the newimmigrant documents for admission to LPR as a "new arrival."

There are uncertainties about the indirect administrative-data measure, given that nonimmigrant visas can often be extended, and thus we exclude it from our basic global measure of visa overstay experience. Moreover, for the FY 1996 cohort, the public-use administrative microdata do not include records of IRCA-legalized persons, and hence there is no information in the data for overstays who legalize under special legalization programs. Thus, the basic global measure of overstay experience used in this paper is based on the direct NIS-P measure and the two measures based jointly on NIS-P and administrative data.

Because respondents who had made multiple trips to the United States may have overstayed a visa at some time before the last trip and not revealed it in response to the 12-month round question, we believe that the global visa overstay measure may also understate the true extent of visa overstay experience among new legal immigrants. However, as with EWI experience (discussed in the preceding section), the potential for unmeasured overstay experience is limited. Among new-arrival immigrants, the proportion who made more than two trips to the United States and whose first trip was not as an LPR and who do not report overstay experience 
- the proportion at risk of unmeasured overstay experience -- is $12 \%{ }^{22}$

\subsubsection{Unauthorized Employment}

Although neither administrative data nor NIS-P data provide direct information on employment without authorization, it is possible to infer unauthorized employment by combining the two data sources (Table 1, panel C). The general idea is that if at the baseline round a respondent reports that the current job in the United States began at a date preceding the date of admission to LPR, then there is a possibility that such employment was unauthorized. ${ }^{23}$ However, such work is not unauthorized if the respondent is adjusting status and either of four conditions hold: (1) the nonimmigrant visa from which the respondent is adjusting status permits employment (examples include temporary worker visas and refugee visas); (2) the nonimmigrant visa from which the respondent is adjusting status does not prohibit employment, and the respondent applied for, and was granted employment authorization, via the I-765 application (examples include certain parolee visas and visas held by family members of diplomatic personnel and exchange visitors); (3) the respondent is from a country whose nationals are eligible for temporary protected status (TPS); ${ }^{24}$ or (4) during the adjustment application processing period, the respondent applied for, and was granted, employment authorization, via the I-765 application.

For example, a respondent adjusting from a refugee nonimmigrant visa who reports that the current job started five years before adjustment to LPR would have been fully authorized to work. In contrast, a respondent who reports that the current job started five years earlier and who is adjusting from a tourist visa and also is not from one of the TPS-eligible countries was

22 Within this group, 15\% register other kinds of illegal experience.

23 In drawing inferences about previous unauthorized employment, care must be taken to ensure that the date the current job started pertains to a job in the United States. It is possible for new legal immigrants to retain a job in their previous country, and such a job, of course, would provide no evidence of unauthorized employment in the United States.

24 Countries whose nationals were eligible for temporary protected status in the years before 1996 were Bosnia and Herzegovina (since 1992), Rwanda (since 1994), and Somalia (since 1991). 
probably working illegally, at least until being granted employment authorization during the time that the application for adjustment to LPR was being processed.

The main challenge lies in discerning the timing of the application for adjustment among respondents from non-TPS countries who had nonimmigrant visas prohibiting employment. For example, if the visa processing period lasted one year, then the respondent's employment during that year would be legal. However, if the date the U.S. job started precedes the date the application was filed and visa processing began, then the respondent would have been working illegally for that interval. It may be possible - and future research along these lines would be useful - to use INS/CIS workload information in conjunction with the immigrant's geographic residence to estimate the date that processing began for each respondent. For now, notwithstanding the well-known fact that processing delays vary across INS/CIS offices, we apply the same average processing delay to all respondents, and, as a sensitivity test, construct measures which vary the length of the processing period.

Reasoning along these lines enables construction of several measures of illegal work experience, based jointly on administrative and NIS-P data, as follows:

First, if the respondent is a new arrival and reports that the current U.S. job began before the date of admission to LPR, and the visa category is not among those which let nonimmigrants living in the U.S. choose consular processing, we infer unauthorized employment.

Second, if the respondent is an adjustee whose current U.S. job began before the date of admission to LPR and the nonimmigrant visa held before adjustment prohibits employment and the origin country is not one whose nationals are granted temporary protected status, then we use the information on date the job started to code unauthorized employment on several measures defined by the length of the visa processing period - from half a year to 3 years in half-year steps.

Thus, for example, an adjustee who reports that the current U.S. job began 2.5 years before admission to LPR (and who was not eligible for temporary protected status and whose nonimmigrant visa prohibited employment) would be coded as having engaged in unauthorized employment in the measures stipulating a length of the adjustment processing period shorter than 
2.5 years but would be coded as not having illegal work experience in the measure setting the length of the adjustment processing period at 3 years.

Finally, we constructed a basic global measure of illegal work experience, covering both the new-arrival immigrants and the adjustee immigrants. We estimated two versions, assuming one and two years of adjustment processing, respectively.

Do these basic global measures under- or overstate the proportion who have worked without authorization? Note that we assume that all respondents who wanted to work and who were eligible for employment authorization (I-765) - i.e., nonimmigrants whose visas do not prohibit employment and adjustment applicants - applied for, and were granted, employment authorization, thus reducing the proportion with illegal work experience. Moreover, the new immigrants may have had illegal work experience at some earlier time in their lives. Thus, we believe that our measures of illegal work experience may understate the true extent of illegal work experience.

\subsubsection{Unspecified Illegal Experience}

Administrative data provide three measures of illegal experience whose type cannot be unambiguously inferred. These cover immigrants who acquire LPR under the registry or suspension-of-deportation/cancellation-of-removal provisions of U.S. immigration law or under

some special legalization programs (Table 1, panel D). Similarly, NIS-P data provide a measure of having been apprehended by the INS, without information on the type of illegality.

Administrative data for FY 1996 do not include any pertinent information based on special legalization programs. The other two measures based on administrative data cover immigrants who obtained LPR via the registry and suspension-of-deportation/cancellation-ofremoval provisions. All immigrants in these visa categories are adjustees, and they receive nonimmigrant codes of EWI, UU, or the code corresponding to their nonimmigrant visa. If they receive the EWI code, then their type of illegal experience is known and we do not include them in this unspecified illegal experience grouping. Accordingly, we constructed measures which distinguish both between the registry and the suspension-of-deportation/cancellation-of-removal 
provisions and between the UU and other (non-EWI) nonimmigrant codes. ${ }^{25}$

Finally, we construct a basic global measure of unspecified illegal experience which includes the two administrative-data measures and the INS apprehension measure.

\subsubsection{Remarks on Measures of Previous Illegal Experience}

Visual inspection of Table 1 reveals three interesting things. First, administrative data provide information on previous illegal experience only for adjustees; they are silent about previous illegal experience of new arrivals. Second, administrative data provide information only about immediately previous illegal experience, not about illegal experience at some time in the past earlier than the process which led to LPR. Third, administrative data provide direct information about EWI experience and, in some cases, about overstay experience; indirect information about overstay experience; but no information about working without authorization. Whether the emphasis on entry without inspection is cause or effect of official data systems is a topic for future research.

\section{RESULTS}

\subsection{Basic Estimates of Previous Illegal Experience, by Type of Illegality}

Table 2 reports the proportion of the FY 1996 NIS-P immigrants age 18 and older at admission to LPR with previous illegal experience, by type of illegality and data source. ${ }^{26}$ All percentages reflect use of sampling weights to adjust for the oversampling of employment

25 Put differently, the type of illegal experience is unknown for the registry and suspension-of-deportation/cancellation-of-removal immigrants, and we make no inference about it; however, given the notion that the UU code may signal EWI experience, for the convenience of the reader, we report separately the subset with a UU code and the subset with a code other than EWI or UU. As will be seen below (Table 2), the proportions in these subsets of unspecified illegal experience are minuscule.

26

As noted in section 2 and evident in Table 2, the measures on which our estimates are based do not include the following three kinds of measures: (1) administrative measures based on special legalization programs (because the NIS-P sampling frame excludes the small set of IRCA immigrants); (2) the measure based on the UU nonimmigrant code; and (3) the indirect measure of overstay experience based on the nonimmigrant class and date (Warren unpubl). However, below we examine how inclusion of the UU and indirect overstay measure would alter the estimates. 
immigrants. Because immigrants may in some cases register illegal experience in several indicators, the total with illegal experience of a given type (for example, EWI) is less than the sum of the proportions in each of that type's indicators (for example, each of the EWI indicators). Similarly, because immigrants may have illegal experience of several types, the total with illegal experience is less than the sum of the proportions in each illegal type. The estimates are based on sample data and thus are subject to sampling variability. ${ }^{27}$ Moreover, the estimates are for only one cohort; as noted above, cohorts may vary considerably with respect to immigrant characteristics (Jasso 2004), including previous illegal experience. ${ }^{28}$

- Table 2 about here -

Entry without Inspection. As shown in Table 2, panel A, we estimate that 17.2 percent of the NIS-P immigrants entered without documents on the first trip to the United States, 12.3 percent were adjustees with the WI code, and, as expected, less than 1 percent entered without documents on the last trip before the baseline interview. The total set of immigrants with some EWI experience constitutes $19.2 \%$ of the sample; the $95 \%$ confidence interval extends from $16.9 \%$ to $21.5 \%{ }^{29}$

Visa Overstay. Eight percent of the sample reported visa overstay experience in the

27 Throughout the paper we present point estimates, reporting confidence intervals only for the major measures.

28

There are inconsistencies in 20 new-arrival cases in the NIS-P data. In these cases, the date (month and year) the immigrant reports entering for the very first time is the same as (or, in 5 cases, later than) the date of admission to LPR (which is on the official immigrant record and formed the basis for drawing the sample). In seventeen of these cases the immigrant also reports that the entry that first time was without documents, and in 3 cases, the immigrant reports having visa overstay experience (one of the latter also reporting having been apprehended by INS). Because an undocumented entry or a visa overstay would be more likely to be remembered correctly than the date of first entry, we code these 20 cases based on the EWI or overstay information. However, for each global measure of type of illegal experience and for the total estimate, we note the corresponding figure if the 20 cases did not in fact have illegal experience.

29 If the 20 cases with the inconsistency are excluded, the estimate of the proportion with EWI experience is $17.4 \%$, a reduction of 1.8 percentage points. 
NIS-P. ${ }^{30}$ The total with visa overstay experience, inclusive of immigrants for whom visa overstay was inferred from the dates of trips to the United States and of admission to LPR, is $11.9 \%$, with a $95 \%$ confidence interval of $[10 \%, 13.8 \%]^{31}$

Employment without Authorization. Our measures of unauthorized employment indicate that the proportion working illegally could have been as high as 13 percent, if the visa processing period only lasted 6 months (11.7\% consisting of adjustees and $1.2 \%$ of new arrivals), or as low as $6 \%$, if the visa processing period lasted 3 years. Our current information suggests that a reasonable estimate of visa processing time for adjustment applicants in the FY 1996 cohort would be one year. Accordingly, our preferred estimate puts the proportion with illegal work experience at 10.7 percent, with a 95\% confidence interval of $[8.8 \%, 12.5 \%]$.

Unspecified Illegal Experience. A little less than two percent (1.75\%) of the sample reported having been apprehended by INS. ${ }^{32}$ Adding tiny proportions in the registry and suspension-of-deportation categories brings the total with unspecified illegal experience to 2.22 percent.

Total Previous Illegal Experience. Combining the four basic global measures of previous illegal experience - EWI, visa overstay, unauthorized employment, plus unspecified illegal experience - and using the preferred one-year estimate for adjustment visa processing, we obtain

30

The question on visa overstay experience was asked at the 12-month round; it was asked only of respondents who indicated that they had been in the United States prior to obtaining LPR. The proportion of these respondents who responded in the affirmative is $17.6 \%$; the proportion of all the 12-month respondents who said they had overstay experience is $9.7 \%$.

31 If the 20 cases with the previously discussed inconsistency are excluded, the estimate of the proportion with visa overstay experience is $11.5 \%$, a reduction of less than half a percentage point.

32 The question on apprehension was asked at the 12-month round; like the question on overstay experience, it was asked only of respondents who indicated they had been in the United States before achieving LPR. The proportion of these respondents who answered in the affirmative is $3.7 \%$; the proportion among all the 12-month respondents who indicated they had been apprehended is $2.0 \%$. This small proportion raises the question whether illegals who are successful in becoming LPRs are also successful in eluding apprehension. Alternatively, there may be a stigma associated with apprehension such that respondents may be reluctant to reveal this part of their history. 
an estimate of $31.7 \%$ (Table 2). Thus, approximately 32 percent of the new legal immigrants in the FY 1996 cohort have some kind of previous illegal experience; the 95\% confidence interval around the estimate of $31.7 \%$ is $[29 \%, 34.4 \%]{ }^{33}$

\subsection{Composition of the Formerly Illegal Population, by Type of Illegal Experience}

The figures in Table 2 indicate that $60.7 \%$ of the formerly illegal new legal immigrants have EWI experience, $37.5 \%$ have overstay experience, and $33.7 \%$ have experience working without authorization. Only about $10.8 \%$ of those with previous illegal experience had unauthorized employment only, that is, had valid temporary visas whose employment restrictions they were violating; in this group almost two-thirds had B2 tourist ("visitor for pleasure") visas.

\subsection{Modifications to the Basic Estimates}

If we include the UU-coded immigrants, the point estimate for previous illegal experience increases from $31.7 \%$ to $33.3 \%$, a net increase of 1.59 percentage points. If we instead include our modified version of the Warren (unpubl) measure of overstay experience, the estimate increases to $33.2 \%$ - a net increase of 1.52 percentage points. ${ }^{34}$ Finally, if we include both the UU-coded immigrants and the Warren (unpubl) overstay measure, the estimate increases to $34.8 \%$, a net increase of 3.11 percentage points.

\subsection{Estimates of Previous Illegal Experience without Survey Data}

Suppose all we had were the public-use administrative microdata. Or suppose that government officials have access not only to the public-use administrative microdata but also to records of apprehension. What would be the estimates?

Table 3 reports three sets of estimates based on three data-source scenarios: (1) publicuse administrative microdata alone; (2) public-use administrative microdata plus information on apprehension, approximated by the NIS-P apprehension data; and (3) full use of both public-use

33

If the 20 cases with the inconsistency are excluded, the estimate of total previous illegal experience is $29.5 \%$, a reduction of 2.2 percentage points.

34 Two reasons account for the small increase: (1) the total number of cases with B2 or WT nonimmigrant codes and year of entry prior to 1990 is small (51 cases); and (2) almost twothirds $(65.5 \%)$ of them register previous illegal experience in one or more of the other measures. 
administrative microdata and survey data. The first row of the table reports the basic estimates; for example, the estimate in the rightmost column is the preferred estimate of $31.7 \%$ from Table 2. As shown, the estimates obtained from public-use administrative microdata alone or publicuse administrative microdata plus the INS apprehension measure hover about 13 percent, substantially lower than the estimate of $31.7 \%$ obtained by using both administrative and survey data.

\section{- Table 3 about here -}

Table 3 also reports the modifications obtained by including the UU measure and the indirect visa overstay measure, as discussed in section 3.3 above. As shown, the estimates based on public-use administrative microdata alone and on public-use administrative microdata plus the apprehension measure both increase by almost 8 percentage points, from $12.8 \%$ to $20.7 \%$ and $13.5 \%$ to $21.1 \%$, respectively. The fuller measure, however, only increases by 3 percentage points, indicating the substantial overlap between the two additional administrative measures and the survey data. The pure public-use administrative microdata measure now registers $59 \%$ of the full measure. While much further research is needed, these results suggest that estimates of previous illegal experience on the large set of cohorts for which public-use administrative microdata are available might fruitfully use all the measures in Table 1, including those based on the UU nonimmigrant code and the indirect visa overstay measure used by Warren (unpubl).

These results also suggest that at best, the government knows about the previous illegal experience of approximately $61 \%$ of those with such experience. Of course, the government may have superior information. However, given that eluding detection is the goal of illegal migrants, any government estimate may fall short of the estimates reported in this paper, which are based on information freely provided to scientific researchers by new legal immigrants.

\section{PREVIOUS ILLEGAL EXPERIENCE BY IMMIGRANT CHARACTERISTICS}

\subsection{Previous Illegal Experience, by Demographic and Visa Characteristics}

Table 4 reports the proportions with previous illegal experience by visa category, region 
of origin, and religion, as well as among immigrants with very low and very high levels of schooling, both for the sample as a whole and separately by gender. ${ }^{35}$

- Table 4 about here -

Gender. Men are 1.5 times more likely than women to have previous illegal experience 39 percent of the male respondents had illegal experience, compared with 26 percent of the women (Table 4, bottom row). This gender difference is consistent with the findings of Cerrutti and Massey (2001), which show that among Mexican immigrants, women almost always follow men in the migration sequence: wives migrate after husbands and daughters follow fathers.

Schooling. Not surprisingly, among immigrants with less than 9 years of schooling, $46 \%$ have previous illegal experience. However, even among highly educated immigrants - those with $17+$ years of schooling -- the proportion with previous illegal experience is not trivial: 23.3 percent.

Visa Category. An important feature of U.S. immigration is that the characteristics of immigrants differ substantially across visa classes. For example, as described in Jasso, Massey, Rosenzweig, and Smith (2000ab), immigrants qualifying for LPR via different provisions of immigration law differ in years of schooling, knowledge of English, earnings, and earnings gain. Moreover, there are several reasons for expecting, a priori, differences in previous illegal experience across visa categories: First, marriage to a U.S. citizen may be an appealing pathway to immigration for someone who is in an illegal status in the United States; this mechanism would be visible in the visa class for spouses of U.S. citizens married less than two years. Second, the pre-existing spouses of IRCA-legalized aliens would appear in the spouse-of-U.S.citizen category with marriages of greater than two years' duration (given that IRCA-legalized aliens started becoming eligible to naturalize in FY 1994) and in the spouse-of-LPR-category. 36

35 All estimates in this section and the next are based on our preferred basic estimates i.e., based on 1 year of adjustment processing and excluding the UU and indirect visa overstay measures.

36 The backlog in the visa category for spouses of permanent resident aliens ensures that all new immigrants in this category have been married more than two years. 
Accordingly, we examine previous illegal experience by visa category.

Table 4 reports the proportions with previous illegal experience by visa category, both for the sample as a whole and separately by gender. As expected, the three marriage categories figure prominently. Among men, the two categories with the largest fractions with previous illegal experience are both spouse-of-U.S.-citizen categories, with $73 \%$ of the old-married and $47 \%$ of the newlywed husbands having previous illegal experience. Among women, the two largest categories, with almost equal percentages of $57-58 \%$, are the old-married and the spouseof-LPR categories. These figures suggest that among women, previous illegal experience is heavily linked with the aftermath of the IRCA legalization program, while among men, there are both strong currents of an IRCA aftermath (interestingly, with energetic wives who legalized and naturalized) and of a continuing appeal to potential American brides. ${ }^{37}$

Table 4 also provides evidence that previous illegal experience is strong among men who immigrate as parents of U.S. citizens and as employment principals (both $38 \%$ ), with previouslyillegal women also showing strength in the employment principal category (31\%). Both these figures suggest that the illegal phenomenon is not confined to the young or, given the requirements for most employment-based visas, to the unskilled.

These results also indicate that diversity immigrants have nontrivial amounts of previous illegal experience $-27 \%$ of the men and $14 \%$ of the women.

If we eliminate the three spouse categories, the overall proportion of new immigrants with previous illegal experience is 25.1 percent, and the sex-specific proportions are 32.7 percent and 17.7 percent, among men and women, respectively. If we eliminate only the two categories of spouses married more than two years - to eliminate all the immigrant spouses in pre-existing marriages who could have been sponsored by IRCA-legalized aliens - the overall proportion with illegal experience is 30.7 percent, and the sex-specific proportions are 47.1 percent and 20.2

37 Among the Mexico-born spouse-of-U.S.-citizen immigrants, there is a substantial schooling differential between the old-married and the newly-married, suggesting that the oldmarried are more likely to be sponsored by IRCA-legalized aliens (Jasso, Massey, Rosenzweig, and Smith 2000a:452-454). 
percent, respectively, among men and women. Thus, even without the aftermath of IRCA, the proportion with previous illegal experience is still high. 38

$\underline{\text { Region of Birth. }}$ The figures for previous illegal experience by continent of origin (Table 4, panel B) show, as expected, large percentages among immigrants from the Western Hemisphere, but the fractions with illegal experience among immigrants from other parts of the world are not trivial - for example, among men, 28 percent of immigrants from Africa and 24 percent of immigrants from Europe have previous illegal experience.

To further explore region of origin, we examine the percentages with previous illegal experience in selected countries of birth (panel D). ${ }^{39}$ The country with the highest proportions is Mexico; $85 \%$ of the men and $67 \%$ of the women have prior illegal experience. Other countries with high fractions with previous illegal experience are El Salvador $(72 \%$ of men and $60 \%$ of women), Dominican Republic (62\% of men and $33 \%$ of women), and Poland (55\% of men and $17 \%$ of women). Sample sizes unfortunately do not permit a finer look within visa category and country. It will be useful, with the larger sample size of the full NIS, to explore differences in the gender composition of previously illegal legals across origin countries.

$\underline{\text { Religion. }}$ The large fractions with previous illegal experience among Catholics and Protestants (Table 4, panel C) are not a surprise, given their representation among immigrants from Mexico. However, it is of interest that, among men, Muslims have almost as high a fraction with previous illegal experience as do Catholics (47.3\% versus 47.7\%).

38 Of course, the U.S. citizen sponsors of newlywed spouses may include some IRCAlegalized individuals. Approximately 38 percent of the pre-1982 legalization subset were single or otherwise unattached during the first phase of legalization (U.S. INS, 1992, Report on the Legalized Alien Population, p. 21). Eventually they would be able to choose a mate from among several subsets, including native-born U.S. citizens but including as well three subsets in need of visa sponsorship: foreign-born individuals residing outside the United States; foreign-born individuals with a valid temporary visa in the United States; and foreign-born individuals illegally in the United States. Only marriages to individuals in the last subset would produce an IRCA effect in the estimated proportion with previous illegal experience, among newlywed spouses of U.S. citizens.

39 Below we take a different tack, assessing the top origin countries among the formerly illegal. 
Finally, Table 4 signals the possibility of interesting gender-specific patterns. While in almost all the visa categories, origin countries, and religious affiliations, more men than women have previous illegal experience - the main exceptions are (1) spouse of LPR, among visa categories, (2) India and the Philippines, among origin countries, and (3) Protestants and Buddhists, among religious affiliations -- the magnitude of the gender difference varies widely. Further research, with the ample sample size of the full NIS, appears warranted.

\subsection{Multivariate Models of Previous Illegal Experience}

The results reported in Table 4 are gross of all immigrant characteristics, and thus the question arises whether the associations survive controls for covariates. To assess operation of the characteristics highlighted in Table 4 in a multivariate context, we analyze the probability that the new legal immigrants have previous illegal experience. Table 5 reports five binary logit specifications.

\section{- Table 5 about here -}

All specifications include gender, age, and age-squared. Four of the five specifications (all except (5)) include schooling. Specification (2) adds binary variables for visa categories and religion categories, and specification (3) adds binary variables for selected origin countries. Specification (4) deletes the visa and religion variables, retaining the country dummies. Finally, specification (5) deletes schooling, again retaining the country dummies.

In all specifications, gender (coded " 1 " for females) is statistically significant and negative, indicating that, as in Table 4, women are less likely than men to have previous illegal experience, other things the same.

Schooling exerts a statistically significant negative effect on the probability of previous illegal experience in all specifications, although the magnitude of the effect is sensitive to the presence of the origin-country variables, declining in absolute value in specifications (3) and (4). This decline suggests that at least a portion of the schooling effect has its origin in country mechanisms. Nonetheless, controlling for origin country, the probability of illegal experience is lower, the greater the schooling. 
Specification 2 adds comprehensive sets of visa categories (11 broad visa categories) and religion categories ( 8 categories). To save space, we report the joint test of statistical significance for the sets of coefficients representing the operation of visa and religion (and, later, of origin country), but omit the coefficients for each of the included categories. The visa dummies are jointly significant, as are the religion dummies. However, specification (3), which adds a set of dummies for country of birth (16 dummies) shows that origin country overwhelms the visa and religion effects, wiping out their statistical significance (and indeed that of age). Clearly there are pervasive effects associated with origin country, only some of which are captured by respondents' religious preference and their routes to acquiring legal permanent residence.

Specification (4) eliminates the religion and visa dummies, retaining age, age-squared, schooling, and the country dummies. Age and age-squared regain statistical significance; gender, schooling, and the country dummies keep it.

Finally, specification (5) deletes schooling, retaining the unambiguously exogenous variables - age, age-squared, country of birth, and gender. Deletion of schooling preserves all the effects visible in specification (4). Birth country shows itself a powerful engine of all that is to come. The coefficients of age and age-squared suggest that the probability of previous illegal experience increases until about age $38-40$, and subsequently decreases.

In sum, four of the six variables in our models - gender, age, schooling, and origin country - appear to be responsible for most of the variation in the probability of illegal experience. It is useful to speculate about the mechanisms involved. Consider schooling, for example. How does schooling reduce the probability of illegal experience? One set of mechanisms is rooted in U.S. society and U.S. immigration law. Persons with more schooling are more likely to qualify for lawful permanent residence. Of the approximately 140,000 visas available annually based on employment, all but 10,000 (5,000 since 2002) are for persons with 
substantial schooling or entrepreneurial skills. ${ }^{40}$ Eligibility for the 50,000 diversity visas requires that the principal have a high school education or the equivalent. Finally, behavioral mechanisms militate for high levels of schooling among persons who achieve LPR as the spouses of U.S. citizens - the largest single group of adult immigrants, about $27-33 \%$ each year -- given assortative mating and the high levels of Americans' schooling. Meanwhile, prospective immigrants with lower schooling levels find fewer opportunities for legal migration and, depending on conditions in their home countries, may opt for life as an illegal. ${ }^{41}$

Further research, on more cohorts, is needed to achieve fuller understanding of the factors which promote or impede illegal experience, with the attendant hardships, moral as well as physical, and to investigate gender-specific patterns. For now, it would appear that, consistent with the analyses and interpretations in Jasso, Rosenzweig, and Smith (2000) and Massey, Durand, and Malone (2002), countries play a large part in both investment in human resources and returns to human resources and, concomitantly, individuals, seeking to improve their lives, respond to perceived opportunities and follow paths successfully traversed by others. How these factors interact to produce illegal experience - and to overcome illegal experience, by achieving LPR - is a question at the top of the agenda for future work.

\section{ORIGINS AND DESTINATIONS OF THE FORMERLY ILLEGAL}

We have seen the proportions of new legal immigrants from different countries and regions of the world who have previous illegal experience. In this section, we examine the origin countries and states of residence of the formerly illegal, contrasting them first with those FY 1996 immigrants who do not have previous illegal experience and next with estimates of the total illegal population in the United States.

40

These figures include visas for spouses and children of employment principals.

41 Of course, persons with low schooling levels also qualify for an immigrant visa. Persons whose grown children have made successful lives in the United States can immigrate as parents of U.S. citizens, without regard to schooling; refugees are welcomed, without regard to schooling; and spouses of highly-schooled principals need not be highly schooled themselves. 


\subsection{Comparing NIS-P Immigrants With and Without Previous Illegal Experience}

\subsubsection{Top Five Origin Countries}

Table 6 reports, in panel A, the top five origin countries for the formerly illegal in the FY 1996 cohort, separately for men and women. Only two countries appear in the top five for both men and women - Mexico, which ranks at the top among both, and the Dominican Republic. Among men, the other three countries in the top five are Colombia, Guatemala, and Poland. Among women, they are El Salvador, Peru, and the Philippines.

\section{- Table 6 about here --}

Thus, while among both sexes, the subcohorts with previous illegal experience are dominated by immigrants from the Western Hemisphere, the male subcohort has a European element and the female subcohort an Asian one.

The magnitude of the Mexico dominance is substantially greater among women than among men $-45 \%$ of the formerly illegal women are from Mexico versus $27 \%$ of the men -suggesting yet again that the FY 1996 cohort reflects the IRCA aftermath. But the Mexico dominance is pronounced in both sexes. The second top origin country barely represents more than five percent of the formerly illegal among men, and does not reach five percent among women.

These figures also indicate that formerly illegal women are more highly concentrated by origin country than are formerly illegal men. While $46 \%$ of the formerly illegal men come from the top five countries, $62 \%$ of the women do so. This, too, reflects the IRCA aftermath.

Origin country patterns differ markedly among cohort members who do not have previous illegal experience (Table 6, panel B). In this latter group, only $34 \%$ of the men and $33 \%$ of the women originate in the top five countries - far smaller concentrations than the corresponding figures of $46 \%$ and $62 \%$ among immigrants with previous illegal experience.

\subsubsection{Top Five States of Residence}

Table 7 reports the top five states of residence among new legal immigrants. As shown in Table 7, panel A, the same five states, albeit in different ordering, rank as the top destinations for 
both men and women among the formerly illegal new legal immigrants in the FY 1996 cohort California, Texas, New York, New Jersey, and Florida. While among men, New York ranks at the top, among women California ranks first, consistent with the IRCA aftermath interpretation. Texas ranks second among both sexes.

\section{- Table 7 about here -}

The choice of destination among the formerly illegal new legal immigrants is also highly concentrated. Seventy percent of the men and 79 percent of the women are found in the top five states.

Male immigrants without previous illegal experience settle in the same top five states as their formerly illegal counterparts, but they are less concentrated (Table 7, panel B) - 64\% are in the top five states of residence versus $70 \%$ among the formerly illegal. Among women, the two sets of top five states differ only in the state in fifth place, Florida among the formerly illegal and Illinois among immigrants with no illegal experience. However, women with no illegal experience are substantially less concentrated $-62 \%$ are in the top five states versus $79 \%$ among the formerly illegal.

\subsection{Comparing the Formerly Illegal new Legal Immigrants}

\section{with the Larger Illegal Population}

We have compared the origins and destinations of the formerly illegal in the FY 1996 cohort sample with those of their counterparts who did not have previous illegal experience. The question naturally arises whether the formerly illegal new legal immigrants are representative of the larger illegal population. A priori we may conjecture that the answer is no, that illegals who achieve LPR differ from illegals who do not. Those who legalize may be more desirous of residing permanently in the United States and/or may have already qualified for LPR and begun U.S. residence while still in the LPR queue and/or may possess more human or social capital to enable acquiring the green card.

Indeed, a close look at the personal, documentary, and financial requirements for LPR suggests that large numbers of persons around the world are permanently ineligible for LPR, 
lending a surreal air to contemporary political discussion. Saying, "Let them get in line," is like saying, "Let them eat cake." Of course, stardust could fall on the permanently ineligible, in the form of a lottery visa (given the right origin country and the right educational qualifications) or a romantic partner. But for many there is little hope of a regular LPR visa under current immigration law.

These and other considerations suggest that the probability of success in achieving lawful permanent residence may be correlated with origin country and/or with state of residence. Thus, the origins and destinations of the formerly illegal and of the broader illegal population may differ.

Further, even if the formerly illegal new legal immigrants studied in this paper were representative of their agemates in the larger illegal population, the estimates of their origin countries and states of residence could still differ if there are compositional differences by age. Thus, if the origins and destinations of illegal children differ from those of illegal adults, then our estimates of the origins and destinations of the FY 1996 adults could differ from the origins and destinations of the broader illegal population, even if the FY 1996 adults were representative of the adult illegals.

In this section we compare the origins and destinations of the formerly illegal new legal immigrants with two estimates of the total illegal population and a third estimate of the residual foreign-born population. The first estimate of the illegal population was developed by Warren (2003) and reported officially in the DHS 2002 Yearbook; estimates were obtained for 1990 and 2000 and reported by origin country and state of residence. The second estimate of the illegal population was developed by Passel (2002) for the year 2000; estimates were obtained of the proportion from Mexico and the proportions living in the top states of residence. The third estimate taps the residual foreign-born population; estimates were obtained for 1990 and 2000 and reported by origin country. All three estimates to which we compare the FY 1996 formerly illegal new legal immigrant adults pertain to the entire illegal population, including children.

The Costanzo et al. (2002) estimates explicitly include some quasi-legal persons who are 
here legally but not yet counted in the official estimates or are in the visa processing queue. The Passel (2002) estimates also count as illegal a number of classes of individuals who are not currently illegal, such as asylum applicants, persons in temporary protected status, and persons whose applications for adjustment to permanent resident status are pending.

\subsubsection{Top Five Origin Countries}

Table 8 reports, in panel A, the estimated top 5 countries of birth in both the NIS-P, the DHS (2002 Yearbook) and Costanzo et al. (2002) estimates. As shown, only Mexico and El Salvador appear in all three lists. Moreover, while the Passel (2002) figures put Mexico as representing 55\% and the DHS (2002) estimates put it at 58-69\% of the total in 1990 and 2000, respectively, the proportion Mexico-born among the new legal immigrants is only 35 percent, a figure squarely in the range of the Costanzo et al. (2002) estimates (27-45\%).

- Table 8 about here -

The large difference between the NIS-P estimates, on the one hand, and the DHS (2002) and Passel (2002) estimates, on the other, could be due to one or more of the mechanisms noted above, such as: (1) illegal aliens from Mexico are less able to achieve legalization than are illegal aliens from the Dominican Republic, El Salvador, Peru, and Poland; (2) illegal aliens from Mexico are circular migrants and less desirous of legalization than are illegal aliens from the Dominican Republic, El Salvador, Peru, and Poland; and (3) Mexico is overwhelmingly the top origin country of illegal children.

These possibilities signal the importance of further research, for example, studying the legal status of foreign-born children.

As a preliminary reconnaissance, we use the public-use administrative microdata set for the FY 1996 immigrant cohort to examine the origin-country distributions of immigrants whom we can code as illegal based on the EWI nonimmigrant code and the registry and suspension-ofdeportation visa codes, separately for the adult and child subsets of the cohort. The result is rather astounding: while 57.7 percent of the previously-illegal adults are from Mexico, 80.7 percent of the previously-illegal children are from Mexico. Thus, based on limited information 
gleaned from the public-use administrative microdata (recall from Table 3 that the estimated proportion of new immigrants with previous illegal experience is only about $13 \%$ when the public-use measures are used, compared with $32 \%$ when using NIS-P information), it would appear that at least a part of the discrepancy in Mexico origin between our estimates and the DHS (2002) and Passel (2002) estimates is due to large numbers of Mexico-born children in the unauthorized population.

It is interesting as well that the proportion Mexico-born among the adults who can be coded as previously illegal in the public-use INS microdata - $57.7 \%$ - is so similar to the DHS (2002) and Passel (2002) estimates. The INS measure is skewed towards EWI experience (Table 1), so it may be that the DHS and Passel estimates represent proportionately fewer illegals with non-EWI experience. As well, the non-Mexico-born may be more successful at eluding detection, while at the same time the Mexico-born may be less successful at converting their status to that of a lawful permanent resident.

\subsubsection{Top Five States of Residence}

Table 8, panel B, reports the top five states of residence in the three sets of estimates. Both the DHS (2002) and the Passel (2002) estimates yield the same five states as the top states of residence. The NIS-P top five list differs in that it includes New Jersey and excludes Illinois. The proportion in California in the DHS (2002) estimates is 1.5 to 2 times as large as in the NISP, and larger also than in the Passel (2002) estimates.

As with the origin-country estimates, comparison of the geographic-residence estimates suggests three possible mechanisms: (1) illegal aliens residing in California are substantially less able to achieve legalization than are illegal aliens residing in Texas, New York, New Jersey, or Florida: (2) illegal aliens residing in California are circular migrants and less desirous of legalization than are illegal aliens residing in Texas, New York, New Jersey, or Florida; and (3) illegal children are more numerous in California than in the other states. Indeed, the FY 1996 public-use immigrant cohort data confirm that while $34 \%$ of the adults coded as having previous illegal experience (as described above) reside in California, $41.7 \%$ of the children do so. 
Note that the differences between the DHS (2002) and Passel (2002) estimates can be interpreted, in part, as due to the presence in the latter of the legal component discussed above (asylum applicants, persons in temporary protected status, etc.). If this component is less likely to be Mexico-born and more likely to be adult, then its presence would drive down the proportion Mexico-born in the Passel (2002) estimates and as well drive down the proportion children and hence the proportion residing in California.

\subsubsection{Type of Illegal Experience}

Given the foregoing differences between the previously illegal new legal immigrants in the NIS-P and the broader unauthorized population, it is useful to assess one other characteristic available across the estimates - type of illegal experience. The DHS (2002) estimates suggest that two-thirds of the illegal population consists of EWIs and one-third of overstays; no information is provided about either the proportion with unauthorized work experience or the proportion with experience of both EWI and overstay types. Nonetheless, the DHS (2002) and the NIS-P estimates are remarkably consistent: In the NIS-P estimates, $61 \%$ of the formerly illegal have EWI experience and $38 \%$ have overstay experience. ${ }^{42}$

\section{CONCLUDING NOTE}

In this paper we developed a framework for estimating previous illegal experience among annual cohorts of new legal immigrants to the United States - using public-use administrative microdata alone, survey data alone, and the two jointly -- and also provided estimates for the FY 1996 cohort. Our results indicate that 32 percent of the new immigrant adults who were granted permanent residence in FY 1996 had previous illegal experience. Approximately 19 percent of the cohort had experience as an entry without inspection, $12 \%$ had visa overstay experience, and $11 \%$ had engaged in unauthorized employment.

42 The NIS-P estimates are even more similar to INS' (DHS 2002 Yearbook, p. 214) earlier estimate that in October 1996 approximately 59\% of the unauthorized population consisted of EWIs and $41 \%$ of visa overstays. 
Though illegal experience appears widely diffused across demographic characteristics, visa types, and origin countries - for example, 23 percent of new immigrants who are college graduates have illegal experience, as do over a third of employment principals - nonetheless men are more likely to have previous illegal experience than women, the less-schooled more likely than the more highly schooled, and persons from the Americas more likely than immigrants from the rest of the world.

Comparison of new immigrants with and without previous illegal experience indicates that those with illegal experience are substantially more concentrated, both with respect to origin country and to U.S. destination, than those with no previous illegal experience.

Our results also suggest that children may be an important part of the unauthorized population, raising the twin challenges of developing procedures for estimating separately the adult and child components of the unauthorized population and of analyzing the behavioral implications of child illegals both for the children themselves and their families as well as for the schools they attend and the neighborhoods in which they live.

This work suggests several lines for future inquiry, including: (1) refining procedures for use with public-use administrative microdata and survey data, including the 1996, 2003, and future cohorts of the New Immigrant Survey; and (2) estimating previous illegal experience both in the large series of cohorts for which public-use administrative microdata are available (currently Fiscal Years 1972-2000) and also in the NIS cohorts. Both administrative data and survey data differ across cohort, so that different cohorts will present different estimation challenges. For example, as discussed above, information on special legalization programs in administrative data differs across cohort. Similarly, survey data have different information across cohort and/or across survey round; to illustrate, because both asking and answering direct questions about previous illegal experience require a certain comfort level, direct questions about visa overstay and apprehension by the authorities were not asked in the NIS-P until the third round, and have not yet been asked in the NIS-2003 cohort.

Substantively, further research is needed to assess variability across cohort in extent of 
previous illegal experience. If a third of adult new legal immigrants have illegal experience, that is not trivial. It would mean that almost 900 thousand new adult immigrants in the period 19962000 had been illegal and overcame illegality through the actions of employers, spouses, parents, offspring, siblings, and, via the U.S. government, the people of the United States, all presumably tolerant of the illegality -- behavior reminiscent of tolerance for "clandestine immigration".

Of course, there may be large changes in the social and legal environment - for example, due to the events of September 2001 -- and the extent of previous illegal experience may change across cohort.

Finally, this large movement from illegal to legal indicates that at least some foreign-born in the United States experience substantial upward social mobility. 


\section{REFERENCES}

Bean, Frank D., Barry Edmonston, and Jeffrey S. Passel (eds.). 1990. Undocumented Migration to the United States: IRCA and the Experience of the 1980s. Santa Monica, CA, and Washington, DC: RAND Institute and Urban Institute.

Cerrutti, Marcela, and Douglas S. Massey. 2001. "On the Auspices of Female Migration between Mexico and the United States." Demography 38:187-200.

Costanzo, Joseph M., Cynthia Davis, Caribert Irazi, Daniel Goodkind, and Roberto Ramirez. 2002. "Evaluating Components of International Migration: The Residual Foreign Born." Washington, DC: U.S. Bureau of the Census. Population Division, Working Paper \#61.

Durand, Jorge, and Douglas S. Massey. 2004. "The Mexican Migration Project." Pp. 321-36 in Jorge Durand and Douglas S. Massey (eds.), Crossing the Border: Research from the Mexican Migration Project. New York: Russell Sage.

Espenshade, Thomas J. 1995. "Unauthorized Immigration to the United States." Annual Review of Sociology 21:195-216.

Hirschman, Charles. 1978. "Prior U.S. Residence among Mexican Immigrants." Social Forces 56:1179-1202.

Hoefer, Michael, Nancy Rytina, and Christopher Campbell. 2007. "Estimates of the Unauthorized Immigrant Population Residing in the United States: January 2006.” U.S. Department of Homeland Security, Office of Immigration Statistics.

Jasso, Guillermina. 2004. "Have the Occupational Skills of New Legal Immigrants to the United States Changed Over Time? Evidence from the Immigrant Cohorts of 1977, 1982, and 1994." Pp. 261-285 in Douglas S. Massey and J. Edward Taylor (eds.), International Migration: Prospects and Policies in a Global Market. Oxford: Oxford University Press.

Jasso, Guillermina. 2008. "New Immigrant Survey.” Pp. 499-500 in William A. Darity Jr. (ed.), International Encyclopedia of the Social Sciences, Second Edition, Volume 5. Detroit: Macmillan Reference USA. 
Jasso, Guillermina, Douglas S. Massey, Mark R. Rosenzweig, and James P. Smith. 2000a.

"Assortative Mating among Married New Legal Immigrants to the United States:

Evidence from the New Immigrant Survey Pilot." International Migration Review 34:443-459.

Jasso, Guillermina, Douglas S. Massey, Mark R. Rosenzweig, and James P. Smith. 2000b. "The New Immigrant Survey Pilot (NIS-P): Overview and New Findings about U.S. Legal Immigrants at Admission." Demography 37:127-138.

Jasso, Guillermina, Douglas S. Massey, Mark R. Rosenzweig, and James P. Smith. 2003. "The New Immigrant Survey in the U.S.: The Experience over Time." www.migrationinformation.org .

Jasso, Guillermina, Douglas S. Massey, Mark R. Rosenzweig, and James P. Smith. In press. “The U.S. New Immigrant Survey: Overview and Preliminary Results Based on the NewImmigrant Cohorts of 1996 and 2003.” Pp. 29-46 in Beverley Morgan and Ben Nicholson (eds.), Immigration Research and Statistics Service Workshop on Longitudinal Surveys and Cross-Cultural Survey Design: Workshop Proceedings. London, UK: Crown Publishing.

Jasso, Guillermina, and Mark R. Rosenzweig. 1982. "Estimating the Emigration Rates of Legal Immigrants Using Administrative and Survey Data: The 1971 Cohort of Immigrants to the United States." Demography 19:279-290.

Jasso, Guillermina, Mark R. Rosenzweig, and James P. Smith. 2000. "The Changing Skill of New Immigrants to the United States: Recent Trends and Their Determinants." Pp. 185225 in George J. Borjas (ed.), Issues in the Economics of Immigration. Chicago, IL: University of Chicago Press.

Massey, Douglas S. 1987. "Understanding Mexican Migration to the United States." American Journal of Sociology 92:1372-1403.

Massey, Douglas S., Jorge Durand, and Nolan J. Malone. 2002. Beyond Smoke and Mirrors: Mexican Immigration in an Era of Economic Integration. New York, NY: Russell Sage. 
Passel, Jeffrey S. 2002. "New Estimates of the Undocumented Population in the United States."

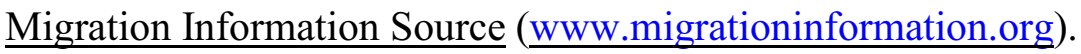

Passel, Jeffrey S., Jennifer Van Hook, and Frank D. Bean. 2006. "Narrative Profile with Adjoining Tables of Unauthorized Migrants and Other Immigrants, Based on Census 2000: Characteristics and Methods." Washington, DC: U.S. Bureau of the Census and Sabre Systems Statistical and Demographic Analyses, Immigration Studies White Papers. Portes, Alejandro. 1979. "Illegal Immigration and the International System, Lessons from Recent Legal Immigrants to the United States. Social Problems 26:425-438. , and Robert L. Bach. 1980. “Immigrant Earnings: Cuban and Mexican Immigrants in the United States.” International Migration Review 14:315-341.

Powers, Mary G., Ellen Percy Kraly, and William Seltzer. 2004. "IRCA: Lessons of the Last Legalization Program.” www.migrationinformation.org . , and William Seltzer. 1998. “Occupational Status and Mobility among Undocumented Immigrants by Gender." International Migration Review 32:21-55.

Singer, Audrey, and Douglas S. Massey. 1998. “The Social Process of Undocumented Border Crossing Among Mexican Migrants.” International Migration Review 32:561-592.

Smith, James P., and Barry Edmonston (eds.). 1997. The New Americans: Economic, Demographic, and Fiscal Effects of Immigration. Report of the National Research Council. Washington, DC: National Academy Press.

U.S. Department of Homeland Security. 2002-2005. Yearbook of Immigration Statistics. Washington, DC: U.S. Government Printing Office.

U.S. Immigration and Naturalization Service. 1992. Immigration Reform and Control Act: Report on the Legalized Alien Population. Washington, DC: U.S. Government Printing Office.

U.S. Immigration and Naturalization Service. 1979-2001. Statistical Yearbook of the Immigration and Naturalization Service. Washington, DC: U.S. Government Printing Office. 
Warren, Robert. 2003. "Estimates of the Unauthorized Immigrant Population Residing in the United States: 1990 to 2000." Available on the DHS website.

. Unpubl. "Detailed Methodology for Annual Estimates of the Unauthorized Immigrant Population Residing in the United States: 1990-2000. 
Table 1. Measures of Previous Illegal Experience, by Type and Data Source

\section{Data Source}

Administrative Record

NIS-P

Both

A. Entry without Inspection

Adjustee, nonimmigrant code WI

Adjustee, nonimmigrant code UU

Adjustee, immigrant code for

special legalization program

No documents on first trip

No documents on last trip

B. Visa Overstay

Adjustee, date of last entry on

nonimmigrant visa too long ago

Adjustee, immigrant code for

special legalization program

Reports overstay

New arrival, first trip only trip, trip date precedes LPR

New arrival, date of last trip precedes LPR

C. Employment without Authorization

New arrival, date started U.S. job precedes LPR

Adjustee, nonimmigrant visa prohibits employment, and date started U.S. job precedes LPR by $\mathrm{x}$ years (too early for employment authorization)

D. Unspecified Illegal Experience

Adjustee, immigrant code for registry provisions

Adjustee, immigrant code for suspension of deportation

Adjustee, immigrant code for special legalization program

Reports INS apprehension

Notes: Immigrant codes for acquiring LPR under special legalization programs may or may not provide information on type of illegal experience. Some examples are: (1) "W16" is for EWIs legalizing under IRCA; (2) "W26" is for overstays legalizing under IRCA; and (3) "NC6" covers legalization under NACARA without regard to the type of illegal experience (DHS 2003 Yearbook, pp. 25-26, 189). 
Table 2. Percent of New Legal Immigrants in FY 1996 with Previous Illegal Experience, by Type of Illegality and Data Source: New Immigrant Survey Pilot Adult Sample

\begin{tabular}{|c|c|c|}
\hline $\begin{array}{c}\text { Data } \\
\text { Source }\end{array}$ & Measure & $\begin{array}{c}\text { FY } 1996 \\
\text { NIS-P }\end{array}$ \\
\hline \multicolumn{3}{|c|}{ A. Entry Without Inspection (EWI) } \\
\hline INS & adjustee, nonimmigrant code WI & 12.3 \\
\hline NIS-P & entered without documents on first trip & 17.2 \\
\hline NIS-P & entered without documents on last trip & .959 \\
\hline Total & & 19.2 \\
\hline
\end{tabular}

B. Visa Overstay

$\begin{array}{lll}\text { NIS-P reports staying longer than authorized } & 8.35\end{array}$

INS+NIS-P new arrival, first trip only trip, date of trip precedes date of adm to LPR $\quad 2.30$

INS+NIS-P new arrival, date of last trip precedes date of admission to LPR $\quad 1.60$

Total

C. Employment without authorization

INS+NIS-P new arrival, date started current U.S. job precedes date of adm to LPR

INS+NIS-P adjustee, date started current U.S. job precedes date of adm to LPR by 6 months and nonimmigrant visa prohibits employment

INS+NIS-P adjustee, date started current U.S. job precedes date of adm to LPR by 1 year and nonimmigrant visa prohibits employment

INS+NIS-P adjustee, date started current U.S. job precedes date of adm to LPR by 1.5 years and nonimmigrant visa prohibits employment

INS+NIS-P adjustee, date started current U.S. job precedes date of adm to LPR by 2 years and nonimmigrant visa prohibits employment

INS+NIS-P adjustee, date started current U.S. job precedes date of adm to LPR by 3 years and nonimmigrant visa prohibits employment

Total (based on 1 year of adjustment processing)

Total (based on 2 years of adjustment processing)

8.84

D. Unspecified illegal experience

INS adjustee, immigrant code Z13/Z14/Z15/Z56, nonimmigrant code UU

INS adjustee, immigrant code Z33/Z03/Z66, nonimmigrant code UU 0

INS adjustee, immigrant code Z13/Z14/Z15/Z56, nonimm code not WI/UU $\quad .116$

INS adjustee, immigrant code Z33/Z03/Z66, nonimmigrant code not WI/UU $\quad .116$

$\begin{array}{lll}\text { NIS-P } \quad \text { reports being apprehended by INS } & 1.75\end{array}$

Total

Total (based on INS and NIS-P data, with 1 year of adjustment processing)

Total (based on INS and NIS-P data, with 2 years of adjustment processing) 
Notes: Estimates based on weighted data to adjust for oversampling of employment-based immigrants. Percentages based on baseline adult sample $(n=1127)$. NIS-P reports of overstay and apprehension obtained at 12 -month round $(n=976)$; percentages based on 12 -month round sample are $9.72 \%$ and $2.04 \%$, respectively. 
Table 3. Percent of New Legal Immigrants in FY 1996 with Previous Illegal Experience, Incorporating Two Additional Measures and by Data Source: New Immigrant Survey Pilot Adult Sample

\begin{tabular}{lccc}
\hline \hline \multicolumn{1}{c}{ Measure } & $\begin{array}{c}\text { Data Source } \\
\text { Public-Use } \\
\text { Public-Use } \\
\text { Administrative } \\
\text { Microdata }\end{array}$ & $\begin{array}{c}\text { Administrative } \\
\text { Microdata } \\
\text { Plus INS } \\
\text { Apprehension } \\
\text { in NIS-P Data }\end{array}$ & $\begin{array}{c}\text { Public-Use } \\
\text { Administrative } \\
\text { Microdata } \\
\text { Plus Full } \\
\text { NIS-P Data }\end{array}$ \\
\hline Basic estimates & 12.8 & 13.5 & 31.7 \\
Also including UU-coded & 16.4 & 17.0 & 33.3 \\
Also including Warren measure & 17.0 & 17.6 & 33.2 \\
Including UU and Warren measures & 20.7 & 21.1 & 34.8 \\
\hline
\end{tabular}

Notes: The basic estimate in the "Public-Use Administrative Microdata" column is based exclusively on public-use microdata, namely, the EWI, registry, and suspension-ofdeportation/cancellation-of-removal measures. The basic estimate in the second column is similar to that in the "Public-Use Administrative Microdata" column except that it includes the NIS-P survey item on apprehension by INS. The basic estimate in the third column includes the full set of measures in Table 2; the basic estimate is the preferred estimate in Table 2, based on one year of adjustment processing. The estimates in the "Public-Use Administrative Microdata" column correspond to the estimates researchers would obtain if there were no survey data or they relied exclusively on public-use administrative microdata. The middle column approximates what government officials might know, if they combine estimates from public-use administrative microdata with information on apprehension. Finally, the rightmost column corresponds to full use of both administrative and survey data using the NIS-P data on the FY 1996 immigrants. 
Table 4. Estimates of Previous Illegal Experience among the FY 1996 Immigrants, by Immigrant Characteristics: New Immigrant Survey Pilot Adult Sample

\begin{tabular}{|c|c|c|c|}
\hline & Men & Women & All \\
\hline \multicolumn{4}{|l|}{ A. Schooling } \\
\hline Schooling under 9 years & 51.0 & 42.4 & 46.0 \\
\hline Schooling over 16 years & 26.1 & 21.1 & 23.3 \\
\hline \multicolumn{4}{|l|}{ B. Visa Category } \\
\hline Spouse of US citizen (marr $<2$ yrs) & 47.1 & 20.2 & 30.7 \\
\hline Spouse of US citizen (marr $>2 \mathrm{yrs}$ ) & 73.0 & 57.6 & 65.7 \\
\hline Spouse of LPR (marr >2 yrs) & 16.7 & 56.5 & 50.0 \\
\hline Parent of US citizen & 37.5 & 12.5 & 20.8 \\
\hline Sibling of US citizen (and spouse) & 23.8 & 15.0 & 19.5 \\
\hline Employment principal & 38.3 & 31.1 & 36.3 \\
\hline Employment spouse & 25.0 & 16.3 & 18.8 \\
\hline $\begin{array}{l}\text { Refugee/asylee/parolee principal and } \\
\text { spouse }\end{array}$ & 18.4 & 4.6 & 11.8 \\
\hline Diversity principal and spouse & 26.9 & 14.3 & 21.3 \\
\hline Other & 40.8 & 25.5 & 33.0 \\
\hline \multicolumn{4}{|l|}{ C. Continent of birth } \\
\hline Africa & 27.6 & 17.3 & 22.8 \\
\hline Asia & 17.0 & 9.8 & 12.9 \\
\hline Europe & 24.1 & 10.6 & 15.8 \\
\hline North America & 64.4 & 53.5 & 58.4 \\
\hline South America & 53.6 & 30.7 & 43.2 \\
\hline \multicolumn{4}{|l|}{ D. Selected countries of birth } \\
\hline China & 18.8 & 4.8 & 11.0 \\
\hline Dominican Republic & 61.5 & 33.3 & 45.2 \\
\hline El Salvador & 71.9 & 60.0 & 65.4 \\
\hline India & 2.0 & 4.6 & 3.6 \\
\hline Jamaica & 33.3 & 32.9 & 33.1 \\
\hline Mexico & 85.3 & 67.2 & 73.7 \\
\hline Philippines & 11.6 & 14.5 & 13.5 \\
\hline Poland & 55.1 & 17.0 & 32.1 \\
\hline Vietnam & 3.9 & 0 & 2.3 \\
\hline
\end{tabular}


E. Religion (based on 12-month round)

\begin{tabular}{lccc} 
Jewish & 3.6 & 0 & 1.5 \\
Christian-Catholic & 47.7 & 35.0 & 40.4 \\
Christian-Orthodox & 40.6 & 15.0 & 26.4 \\
Christian-Protestant & 31.7 & 32.1 & 32.0 \\
Muslim & 47.3 & 17.2 & 30.8 \\
Buddhist & 9.7 & 15.4 & 12.9 \\
Hindu & 18.4 & 8.1 & 13.2 \\
Other religion & 4.1 & 0 & 2.8 \\
No religion & 35.5 & 14.2 & 23.7 \\
\hline \multicolumn{1}{c}{ Total } & 38.7 & 26.1 & 31.7 \\
\hline
\end{tabular}

Note: Cells for women from El Salvador and Jamaica, Jewish men, and Other-religion men and women have fewer than 15 cases. 
Table 5. Binary Logit Models of Previous Illegal Experience among the FY 1996 Immigrants: New Immigrant Survey Pilot Adult Sample

\begin{tabular}{|c|c|c|c|c|c|}
\hline \multirow{2}{*}{ Regressor } & \multicolumn{5}{|c|}{ Specification } \\
\hline & 1 & 2 & 3 & 4 & 5 \\
\hline \multicolumn{6}{|l|}{ Selected estimates } \\
\hline $\operatorname{sex}(1=$ female $)$ & $\begin{array}{l}-.678 \\
(5.0)\end{array}$ & $\begin{array}{l}-.659 \\
(4.02)\end{array}$ & $\begin{array}{l}-.763 \\
(4.28)\end{array}$ & $\begin{array}{l}-.872 \\
(5.70)\end{array}$ & $\begin{array}{l}-.846 \\
(5.60)\end{array}$ \\
\hline age & $\begin{array}{l}.0806 \\
(2.76)\end{array}$ & $\begin{array}{l}.0232 \\
(.64)\end{array}$ & $\begin{array}{l}.0616 \\
(1.54)\end{array}$ & $\begin{array}{l}.118 \\
(3.62)\end{array}$ & $\begin{array}{l}.0966 \\
(3.09)\end{array}$ \\
\hline age squared & $\begin{array}{c}-.00122 \\
(3.38)\end{array}$ & $\begin{array}{c}-.000376 \\
(.85)\end{array}$ & $\begin{array}{c}-.000773 \\
(1.61)\end{array}$ & $\begin{array}{c}-.00155 \\
(3.90)\end{array}$ & $\begin{array}{c}-.00125 \\
(3.32)\end{array}$ \\
\hline schooling (years) & $\begin{array}{c}-.114 \\
(7.31)\end{array}$ & $\begin{array}{l}-.0968 \\
(4.97)\end{array}$ & $\begin{array}{l}-.0589 \\
(2.77)\end{array}$ & $\begin{array}{r}-.0547 \\
(3.09)\end{array}$ & --- \\
\hline constant & $\begin{array}{l}-.114 \\
(.21)\end{array}$ & $\begin{array}{l}.192 \\
(.28)\end{array}$ & $\begin{array}{l}-.926 \\
(1.19)\end{array}$ & $\begin{array}{l}-1.78 \\
(2.82)\end{array}$ & $\begin{array}{l}-2.19 \\
(3.58)\end{array}$ \\
\hline likelihood ratio $\chi^{2}$ & 85.8 & 145.8 & 253.3 & 275.4 & 264.3 \\
\hline df & 4 & 23 & 39 & 20 & 19 \\
\hline \multicolumn{6}{|l|}{ Joint tests, chi squared } \\
\hline age and age squared & 19.85 & 1.44 & 2.59 & 16.4 & 11.7 \\
\hline visa categories $(11)$ & --- & 42.0 & 16.8 & --- & --- \\
\hline religion categories (8) & --- & 19.2 & 9.44 & --- & --- \\
\hline country dummies (16) & --- & --- & 88.7 & 137.4 & 172.7 \\
\hline Number of observations & 1119 & 946 & 946 & 1119 & 1127 \\
\hline
\end{tabular}

Note: Absolute values of asymptotic $t$-ratios under parameter estimates. 
Table 6. Top Five Origin Countries of the FY 1996 Immigrant Cohort, By Previous Illegal Experience: New Immigrant Survey Pilot Adult Sample

\begin{tabular}{|c|c|c|c|c|c|}
\hline \multicolumn{2}{|c|}{ Men } & \multicolumn{2}{|c|}{ Women } & \multicolumn{2}{|c|}{ All } \\
\hline \multicolumn{6}{|c|}{ A. Immigrants with Previous Illegal Experience } \\
\hline Mexico & 26.7 & Mexico & 44.8 & Mexico & 35.0 \\
\hline Colombia & 5.4 & Dom. Rep. & 4.8 & Dom. Rep. & 5.1 \\
\hline Dom. Rep. & 5.4 & El Salvador & 4.8 & El Salvador & 4.3 \\
\hline Guatemala & 4.4 & Peru & 4.0 & Peru & 3.9 \\
\hline Poland & 4.1 & Philippines & 3.8 & Poland & 3.3 \\
\hline Top Five & 45.9 & Top Five & 62.2 & Top Five & 51.6 \\
\hline \multicolumn{6}{|c|}{ B. Immigrants with No Previous Illegal Experience } \\
\hline Vietnam & 10.6 & Mexico & 7.7 & Philippines & 7.5 \\
\hline Philippines & 6.9 & Philippines & 7.9 & Vietnam & 7.1 \\
\hline India & 5.8 & China & 6.4 & China & 6.4 \\
\hline China & 6.5 & India & 5.8 & India & 5.8 \\
\hline UK & 4.4 & Vietnam & 4.8 & Mexico & 5.8 \\
\hline Top Five & 34.1 & Top Five & 32.6 & Top Five & 32.6 \\
\hline
\end{tabular}


Table 7. Top Five Destinations of the FY 1996 Immigrant Cohort, By Previous Illegal Experience: New Immigrant Survey Pilot Adult Sample

\begin{tabular}{|c|c|c|c|c|c|}
\hline \multicolumn{2}{|c|}{ Men } & \multicolumn{2}{|c|}{ Women } & \multicolumn{2}{|c|}{ All } \\
\hline \multicolumn{6}{|c|}{ A. Immigrants with Previous Illegal Experience } \\
\hline New York & 19.9 & California & 26.5 & California & 19.7 \\
\hline Texas & 15.4 & Texas & 21.3 & Texas & 18.1 \\
\hline California & 14.1 & New York & 13.0 & New York & 16.7 \\
\hline Florida & 10.8 & New Jersey & 9.8 & New Jersey & 10.0 \\
\hline New Jersey & 10.1 & Florida & 8.5 & Florida & 9.8 \\
\hline Top Five & 70.3 & Top Five & 79.0 & Top Five & 74.2 \\
\hline \multicolumn{6}{|c|}{ B. Immigrants with No Previous Illegal Experience } \\
\hline New York & 23.9 & California & 23.1 & New York & 20.8 \\
\hline California & 16.7 & New York & 18.7 & California & 20.6 \\
\hline New Jersey & 8.8 & New Jersey & 7.8 & New Jersey & 8.2 \\
\hline Texas & 8.3 & Texas & 7.3 & Texas & 7.7 \\
\hline Florida & 6.3 & Illinois & 4.6 & Florida & 5.0 \\
\hline Top Five & 64.0 & Top Five & 61.6 & Top Five & 62.3 \\
\hline
\end{tabular}


Table 8. Origins and Destinations of the Formerly Illegal in the FY 1996 Immigrant Cohort and of the Larger Illegal Population in 1990 and 2000

\begin{tabular}{|c|c|c|c|c|c|c|c|}
\hline \multirow{2}{*}{\multicolumn{2}{|c|}{$\begin{array}{l}\text { FY } 1996 \text { Immigrants } \\
\text { in the NIS-P }\end{array}$}} & \multicolumn{4}{|c|}{ Illegal Population } & \multirow{2}{*}{\multicolumn{2}{|c|}{$\begin{array}{c}\text { Residual Foreign-Born } \\
\text { 1990-2000 } \\
\text { (Costanzo et al. 2002) }\end{array}$}} \\
\hline & & \multicolumn{2}{|c|}{$\begin{array}{c}1990 \text { to } 2000 \\
\text { (DHS 2002; Warren 2003) }\end{array}$} & \multicolumn{2}{|c|}{$\begin{array}{c}\text { April 2000 } \\
\text { (Passel 2002) } \\
\end{array}$} & & \\
\hline \multicolumn{8}{|c|}{ A. Percent from Top Five Countries of Birth } \\
\hline Mexico & 35.0 & Mexico & 58.3 to 68.7 & Mexico & 55.0 & Mexico & 26.8 to 44.5 \\
\hline Dom. Rep. & 5.1 & El Salvador & 8.5 to 2.7 & --- & --- & El Salvador & 5.4 to 3.87 \\
\hline El Salvador & 4.3 & Guatemala & 3.4 to 2.1 & --- & --- & Cuba & 4.17 to 2.48 \\
\hline Peru & 3.9 & Colombia & 1.4 to 2.0 & --- & --- & China/Taiwan & 3.64 to 2.61 \\
\hline Poland & 3.3 & Honduras & 1.2 to 2.0 & --- & --- & Canada & 3.04 to 1.79 \\
\hline Top Five & 51.6 & Top Five & 72.8 to 77.5 & --- & --- & Top Five & 43.0 to 56.2 \\
\hline \multicolumn{8}{|c|}{ B. Percent in Top Five States of Residence in the United States } \\
\hline California & 19.7 & California & 42.2 to 31.6 & California & 27.1 & --- & --- \\
\hline Texas & 18.1 & Texas & 12.5 to 14.9 & Texas & 14.1 & --- & --- \\
\hline New York & 16.7 & New York & 10.2 to 7.0 & New York & 8.2 & --- & --- \\
\hline New Jersey & 10.0 & Florida & 6.8 to 4.8 & Florida & 8.2 & --- & --- \\
\hline Florida & 9.8 & Illinois & 5.5 to 6.2 & Illinois & 5.9 & --- & --- \\
\hline Top Five & 74.2 & Top Five & 77.2 to 64.5 & Top Five & 63.6 & --- & --- \\
\hline
\end{tabular}

Note: Ranges in the DHS/Warren and Costanzo et al. (2002) estimates are expressed as the figure in 1990 to the figure in 2000. The DHS estimates were published in the 2002 Yearbook. In the Costanzo et al. (2002) estimates, the top five change in 2000, with Guatemala assuming third place $(2.75 \%)$ and India $(2.3 \%)$, Korea $(2.1 \%)$, and Colombia $(2 \%)$, outranking Canada. Numerical estimates for the top five in the Costanzo et al. (2002) estimates for 2000 are for the true top five countries. The Costanzo et al. (2002) estimates include some "quasi-legals" who are here legally but are not yet counted in the official estimates as well as persons in the visa processing queue. 